\title{
Anti-GAD positive stiff-person syndrome and cerebellar ataxia: two treatable conditions that clinicians should be aware of
}

\author{
Síndrome de pessoa-rígida e ataxia cerebelar com teste anti-GAD positivo: duas \\ condições clínicas tratáveis as quais o médico deve permanecer atento
}

Henrique Ballalai Ferraz

Full professor of Neurology, Movement Disorders Unit - Escola

Paulista de Medicina, Federal University of São Paulo (Unifesp), São Paulo SP, Brazil

Correspondence

Henrique Ballalai Ferraz

Disciplina de Neurologia - Unifesp Rua Pedro de Toledo 655

04039-002 São Paulo SP - Brasil

E-mail:henrique_ferraz@uol.com.br

Conflict of interest

There is no conflict of interest to

declare.

Received 04 July 2012

Received in final form 12 July 2012

Accepted 19 July 2012

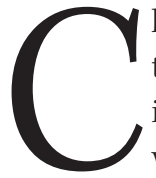

lassical stiff-person syndrome (SPS) is a neurological condition characterized by the slow and progressive contraction of paraspinal and abdominal muscles, leading to typical posture of lumbar hyperlordosis and abnormal neck posture. More widespread cases may affect upper and lower limb muscles ${ }^{1}$. Variants of SPS include stiff limb (exclusive involvement of limbs) and encephalomyelitis with rigidity (cases of generalized rigidity and myoclonus with brainstem neurological additional signs) ${ }^{2}$. In recent years, most cases of SPS and its variants have been tested positive for serum antibodies and for glutamic acid decarboxylase $65 \mathrm{kD}$ isoform (anti-GAD). GAD has a selective expression on central nervous system neurons, secreting gamma-aminobutyric acid (GABA), and on Langerhans beta cells of pancreas ${ }^{3}$. Type I diabetes mellitus and other autoimmune disorders, including thyroid diseases, pernicious anemia and vitiligo may be associated to SMS and its variants $^{2}$. More infrequently, SMS may be a manifestation of paraneoplastic disorders, especially of breast and small cell lung cancer, and these patients may also test positive for antiGAD antibodies ${ }^{4}$.

Anti-GAD antibodies have been shown in some cases of adult-onset cerebellar ataxia without known genetic mutations ${ }^{5}$. These patients are mainly women and may have a chronic or subacute clinical picture of pure ataxia, frequently associated with late-onset type I diabetes. Cerebellar ataxia may have an autoimmune origin in up to $47 \%$ of non-genetic cases, and anti$\mathrm{GAD}$ antibodies are one of the possible etiologies ${ }^{6}$. Unfortunately, we do not know the actual prevalence of anti-GAD cases in a cohort of late-onset cerebellar ataxia patients, but it may not be so frequent. Sivera et al. surveyed anti-GAD antibodies in 44 sporadic adult-onset ataxia patients and none of them tested positive ${ }^{7}$. Malignancy is a well-known cause of cerebellar degeneration and its pathophysiology presumably shares many features with anti-GAD ataxia cases ${ }^{8}$. The spectrum of autoimmune cerebellar ataxia seems to have expanded in recent years. Metabotropic glutamate receptor type 1 autoantibody has been reported in anti-GAD negative cerebellar ataxia cases without associated malignancy ${ }^{9}$. Poor epilepsy control has been associated with anti-GAD antibodies as well.

In this issue, Fernandes et al. show a Brazilian series of nine consecutive SPS and 3 cerebellar ataxia patients testing positive for serum anti-GAD antibodies ${ }^{10}$. Among patients with SPS, four had the classical presentation and five had variants. Variants of SPS were those patients with exclusive limb manifestations of the disease. This series shows that classical SPS, at least in Brazilian patients, may not be the most frequent manifestation of the disorders, and clinicians must be aware of the diagnosis. In a North-American series of 59 patients, only one third of them had variant forms of SPS ${ }^{4}$. Not infrequently SPS is taken for dystonia, spinal deformities, rheumatologic and psychogenic disorders, among others. Good response to any kind of treatment (intravenous immunoglobulin, GABAergic drugs) was obtained in seven out of the nine patients with SPS in this series. This suggests that prescribing antispasmodic drugs (diazepam or baclofen) combined to immunoglobulin may be mandatory to patients diagnosed with SPSs. Our experience shows that anti-GAD positive patients may respond better to 
immunoglobulin than those testing negative. We have seen a woman who was anti-GAD positive with stiff-limb syndrome and has significantly responded to intravenous immunoglobulin for more than 12 years ${ }^{11}$. She could walk independently, shortly after each intravenous infusion, but the positive effect subsided after six months and she had to receive another infusion to improve. She recently died due to lung infection.

In this series, three of the patients had cerebellar ataxia and two of them had evidence of another autoimmune disease (one had type I diabetes mellitus and the other had diabetes combined with Hashimoto's thyroiditis $)^{10}$. Although anti-GAD positive cerebellar ataxia is a rare disorder, it is wise to consider it in patients without known spinal cerebellar atrophy mutations and no evidence of paraneoplastic syndrome, even in the absence of diabetes or another autoimmune disorder. This is particularly important, since it could have a positive result with the immunoglobulin treatment and change the quality of life of patients with this disorder.

\section{References}

1. Thompson PD. Stiff people. In: Marsden CD, Fahn S (Eds). Movement disorders 3. Oxford: Butterworth \& Heinemann Ltda, 1994:373-405.

2. MeinckHM, Thompson PD. Stiff man syndrome and related conditions. Mov Disord 2002;17:853-866.

3. Solimena M, Folli F, Aparisi R, Pozza G, De Camilli P. Autoantibodies to GABA-ergic neurons and pancreatic beta cells in stiff-man syndrome. N Engl J Med 1990;322:1555-1560.

4. McKeon A, Robinson MT, McEvoy KM, Matsumoto JY, Lennon VA, Ahlskoq JE, et al. Stiff-man syndrome and variants: clinical course, treatments, and outcomes. Arch Neurol 2012;69:230-238.

5. Honnorat J, Saiz A, Giometto B, Vincent A, Brieva L, Andres C, et al. Cerebellar ataxia with anti-glutamic acid decarboxylase antibodies: study of 14 patients. Arch Neurol 2001;58:225-230.

6. Hadjivassiliou M, Boscolo S, Tongiorgi E, et al. Cerebellar ataxia as a possible organ-specific autoimmune disease. Mov Disord 2008;23:1370-1377.

7. Sivera R, Martín N, Boscá I, et al. Autoimmunity as a prognostic factor in sporadic adult onset cerebellar ataxia. J Neurol 2012;259:851-854.

8. Panzer J, Dalmau J. Movement disorders in paraneoplastic and autoimmune disease. Curr Opin Neurol 2011;24:346-353.

9. Marignier R, Chenevier F, Rogemond V, et al. Metabotropic glutamate receptor type 1 autoantibody-associated cerebellitis: a primary autoimmune disease? Arch Neurol 2010;67:627-630.

10. Fernandes M, Munhoz RP, Carrilho PEM, et al. Neurological disorders associated with glutamic acid decarboxylase antibodies: a Brazilian series. Arq Neuropsiquiatr 2012;70:657-661.

11. Souza-Lima CF, Ferraz HB, Braz CA, Araujo AM, Manzano GM. Marked improvement in a stiff-limb patient treated with intravenous immunoglobulin. Mov Disord 2000;15:358-359. 